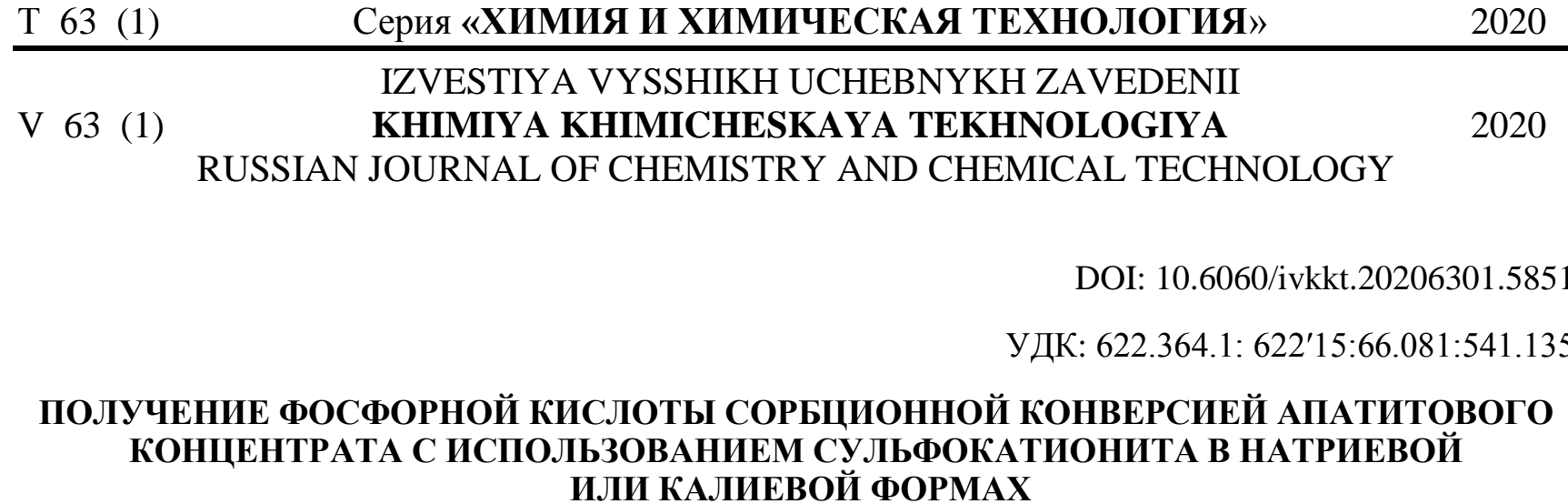

ИЗВЕСТИЯ ВЫСШИХ УЧЕБНЫХ ЗАВЕДЕНИЙ. ИЛИ КАЛИЕВОЙ ФОРМАХ

\author{
Э.П. Локшин, О.А. Тареева, Т.А. Седнева, И.Р. Елизарова
}

Эфроим Пинхусович Локшин*, Ольга Альбертовна Тареева, Татьяна Андреевна Седнева

Лаборатория химии и технологии редкоземельных элементов, Институт химии и технологии редких элементов и минерального сырья им. И.В. Тананаева, ФИЦ Кольский научный центр РАН, Академгородок, 26a, Апатиты, Мурманская область, Российская Федерация, 184209

E-mail: lokshin.ep@gmail.com*, o.tareeva@ksc.ru, t.sedneva@ksc.ru

Ирина Рудольфовна Елизарова

Лаборатория оптических методов анализа, Институт химии и технологии редких элементов и минерального сырья им. И.В. Тананаева, ФИЦ Кольский научный центр РАН, Академгородок, 26а, Апатиты, Мурманская область, Российская Федерация, 184209

E-mail: elizarir@chemy.kolasc.net.ru

Цель работы - продолжение разработки новой эффективной гидрохимической технологии переработки апатитового концентрата, позволяющей получать в качестве продукта фосфорную кислоту с пониженным содержанием примесей, использовать все ценнье компоненты апатитового концентрата. Изучена зависимость эффективности разложения апатитового концентрата фосфорнокислым раствором при температуре 20 и $50{ }^{\circ} \mathrm{C}$ в присутствии сульфокатионита КУ-2-8чС в $\mathrm{Na}^{+}-$и $\mathrm{K}^{+}-$формах. Исследовано влияние условий разложения (расхода и формы сорбента, отночения Ж:Т, температуры взаимодействия) на степень разложения концентрата, полноту поглощения сорбентом основных катионов металлов концентрата, содержание примесей в получающемся фосфорнокислом растворе, состав неразложившихся остатков. Установлена возможность достижения высокой степени разложения концентрата (до 99,5 \%). Показана высокая эффективность сорбции кальция и стронция (до 90,2 и 93,4 \% соответственно). Сорбция РЗЭ цериевой группы проходила лучие, чем РЗЭ средней и иттриевой групп. Увеличение температуры с 20 до $50{ }^{\circ}$ С снижсло сорбцию РЗЭ на 14-170 \%. Наиболее трудно сорбировались алюминий, торий и уран. Найдено, что непосредственно в процессе разложения достигается эффективная очистка фосфорной кислоты от примеси фтора. Эффективность очистки от фтора при использовании сорбента в $\mathrm{K}^{+}$- форме больше, чем при использовании сорбента в $\mathrm{Na}^{+}-$форме. Показана возможность очистки полученной кислоты от натрия или калия методом электродиализа в двухкамерном электродиализаторе, снабженном катионообменной мембраной. Найдено, что перед электродиализом необходима предварительная очистка получаемого в процессе разложения апатитового концентрата фосфорнокислого раствора от кальция. Для этого исследована дополнительная очистка фосфорнокислого раствора сорбцией сульфокатионитом. Более низкая сорбция из фосфорнокислого раствора Al, Ti, Fe, Th и U объяснена образованием этими элементами устойчивых анионных комплексов или недиссоциированных молекул. Разрабатываемая технология получения фосфорной кислоты из апатитового концентрата не требует использования серной кислоты, имеет ряд других преимуществ. Содержание примесей в получаемой фосфорной кислоте значительно меньще, чем в экстракционной фосфорной кислоте, получаемой при сернокислотной переработке апатитового концентрата. 
Ключевые слова: апатитовый концентрат, сорбционная конверсия, получение и очистка фосфорной кислоты

\title{
METHOD OF PHOSPHORIC ACID PRODUCTION BY SORPTION CONVERSION OF APATITE CONCETRATE IN PRESENCE OF SULPHOCATIONITE IN SODIUM OR POTASSIUM FORMS
}

\author{
E.P. Lokshin, O.A. Tareeva, T.A. Sedneva, I.R. Elizarova
}

Efroim P. Lokshin*, Olga A. Tareeva, Tatyana A. Sedneva

Laboratory of Chemistry and Technology of Rare-Earth Elements, Tananaev Institute of Chemistry, FRC Kola Science Centre of RAS, Science Campus, 26, Apatite, 184209, Russia

E-mail: lokshin.ep@gmail.com*, o.tareeva@ksc.ru, t.sedneva@ksc.ru

Irina R. Elizarova

Laboratory of Optical Analysis Methods, Tananaev Institute of Chemistry, FRC Kola Science Centre of RAS, Science Campus, 26, Apatite, 184209, Russia

E-mail: elizarir@chemy.kolasc.net.ru

The aim of the work is the continuation of the development of a new efficient hydrochemical technology for the processing of apatite concentrate, which makes it possible to produce phosphoric acid with a reduced content of impurities as a product, to use all the valuable components of apatite concentrate. The dependence of the efficiency of decomposition of apatite concentrate with a phosphate acid solution at a temperature of 20 and $50{ }^{\circ} \mathrm{C}$ in the presence of sulfate cationite $\mathrm{KY}-2-84 \mathrm{C}$ in $\mathrm{Na}^{+}$- and $\mathrm{K}^{+}$- forms was studied. The influence of the decomposition conditions (expense and form of sorbent, the ratio of liquid: solid, the interaction temperature) on the degree of decomposition of the concentrate, the completeness of absorption by the sorbent of the metallic cations of the concentrate, the content of impurities in the resulting phosphate-acid solution, and the composition of undissolved residues are studied. The possibility of achieving a high degree of decomposition of the concentrate (up to $99.5 \%$ ) is established. High sorption efficiency of calcium and strontium (up to 90.2 and $93.4 \%$ respectively) is shown. The sorption of REE of the cerium group was better than the REE of the middle and yttrium groups. Increasing the temperature from 20 to $50{ }^{\circ} \mathrm{C}$ reduced $\mathrm{REE}$ sorption by $14-170 \%$. Aluminum, thorium and uranium were the most difficult to sorb. It has been found that effective purification of phosphoric acid from the impurity of fluorine is achieved directly in the process of decomposition. The efficiency of purification from fluorine when using a sorbent in the $\mathrm{K}^{+}$- form is greater than when using a sorbent in the $\mathrm{Na}^{+}$- form. It is shown that the obtained acid can be purified from sodium or potassium by the electrodialysis method in a two-chamber electrodialyzer equipped with a cation exchange membrane. It is found that before electrodialysis, preliminary purification of the phosphate solution from calcium, which is obtained during the decomposition of apatite concentrate, is necessary. To this purpose, an additional purification of the phosphoric acid solution by sulphocathionite sorption has been investigated. The lower sorption from the phosphoric acid solution of $\mathrm{Al}, \mathrm{Ti}, \mathrm{Fe}, \mathrm{Th}$, and $\mathrm{U}$ is explained by the formation of stable anionic complexes or undissociated molecules by these elements. The developed technology for the production of phosphoric acid from the apatite concentrate does not require the use of sulfuric acid, has a number of other advantages. The content of impurities in the resulting phosphoric acid is much less than in the extraction phosphoric acid produced by the sulfuric acid processing of apatite concentrate.

Key words: apatite concentrate, sorption conversion, receiving and refining of phosphoric acid 
Для цитирования:

Локшин Э.П., Тареева О.А., Седнева Т.А., Елизарова И.Р. Получение фосфорной кислоты сорбционной конверсией апатитового концентрата с использованием сульфокатионита в натриевой или калиевой формах. Изв. вузов. Химия $u$ хим. технология. 2020. Т. 63. Вып. 1. С. 78-85

For citation:

Lokshin E.P., Tareeva O.A., Sedneva T.A., Elizarova I.R. Method of phosphoric acid production by sorption conversion of apatite concetrate in presence of sulphocationite in sodium. Izv. Vyssh. Uchebn. Zaved. Khim. Khim. Tekhnol. [Russ. J. Chem. \& Chem. Tech.]. 2020. V. 63. N 1. P. 78-85

\section{ВВЕДЕНИЕ}

Апатитовые концентраты являются ценным комплексным сырьем, содержащим кроме фосфора кальций, стронций, редкоземельные элементы (РЗЭ), фтор. С апатитовыми рудами Хибинского массива связана значительная часть российских запасов РЗЭ [1].

Для гидрохимической переработки фосфатного сырья, в том числе апатитовых концентратов, в промышленности используют азотнокислотную и сернокислотную технологии. Исследуется перспективный фосфорнокислотный метод [2].

Азотнокислотная технология обеспечивает высокую степень использования сырья [3, 4], однако, применяется ограниченно, в частности, потому, что не позволяет получать ортофосфорную кислоту.

Фосфорнокислотное разложение [5] позволяет сконцентрировать значительную часть РЗЭ в неразложившемся остатке. Этот метод пока мало разработан, но при его использовании значительная часть наиболее ценных РЗЭ средней и тяжелой групп попадает в фосфорнокислый раствор и теряется.

В России и в мировой промышленной практике наиболее распространена сернокислотная технология переработки апатитовых концентратов. Она обеспечивает высокое извлечение фосфора в товарную продукцию, позволяет извлекать значительную часть фтора. Но при сернокислотной технологии образуется значительное количество пока мало используемого фосфогипса, складирование и хранение которого является технически достаточно сложной задачей [6]. При сернокислотной технологии не извлекаются РЗЭ, основная часть которых переходит в фосфогипс, а меньшая часть попадает в экстракционную фосфорную кислоту и затем в получаемые из нее удобрения.

Из экстракционной фосфорной кислоты РЗЭ могут выделены осаждением концентратов двойных сульфатов с натрием [7] или фтор-фосфатных концентратов, сорбцией на сульфокатионите [8].

Предложен ряд технологий переработки фосфогипса, позволяющих получать качественную кальцийсодержащую продукцию [8-15]. Некото- рые из них предусматривают одновременное извлечение значительной части попадающих в фосфогипс РЗЭ $[14,15]$. Однако, практическое применение разработанных методов пока не началось, и даже если начнется, переработка всего количества образующегося ежегодно фосфогипса останется проблематичной.

Существенные трудности встречает также очистка экстракционной фосфорной кислоты, получающейся при сернокислотном разложении апатитового концентрата $[16,17]$.

Поэтому актуален поиск новых эффективных методов переработки фосфатного сырья.

С целью повышения эффективности переработки апатитового концентрата предложено проводить его разложение раствором фосфорной кислоты с концентрацией 5-38 мас.\% в присутствии сульфоксидного катионита в $\mathrm{H}^{+}$- или $\mathrm{NH}_{4}{ }^{+}$-форме [18]. Получающийся в процессе фосфорнокислый раствор отделяют от содержащего кальций и примесные металлы катионита, очищают известными методами от фтора. В результате может быть получена достаточно чистая фосфорная кислота. Катионит обрабатывают раствором нитрата аммония концентрацией 4-6 моль $\cdot \pi^{-1}$ с переводом кальция и примесных металлов в элюат. Из элюата ступенчатой нейтрализацией смесью аммиака и углекислого газа последовательно осаждают и отделяют содержащий примеси алюминия, железа, титана и тория кек при $\mathrm{pH} 4,2-4,4$, концентрат Р3Э при $\mathrm{pH}$ 7,35-7,5 и смесь карбонатов кальция и стронция при $\mathrm{pH}$ не менее 8,5 [19]. Получающийся при регенерации сульфокатионит в $\mathrm{NH}_{4}{ }^{+}$-форме может быть использован для переработки новой загрузки апатитового концентрата, если получаемую фосфорную кислоту предполагается использовать для производства удобрений на основе фосфатов аммония.

Отличительными чертами такой технологии являются:

- высокая степень комплексности использования сырья с получением фосфатной продукции, соединений фтора, концентрата РЗЭ, карбоната кальция и стронциевого концентрата; 
- высокое извлечение РЗЭ, в том числе иттрия и лантаноидов средней и тяжелой групп;

- энергоэффективность, т.к. разложение апатитового концентрата, переработка сорбента и элюата проводятся при комнатной температуре;

- минимум отходов, представляющих собой неразлагающиеся при переработке акцессорные минералы апатитового концентрата (эгирин, полевые шпаты);

- возможность использования более дешевых материалов для изготовления аппаратуры, коррозионное разрушение которой снижается из-за низкой температуры используемых процессов.

Однако, использование аммиака на удаленных от его производства предприятиях создает организационно-технические проблемы, связанные с доставкой сжиженного аммиака и работой с ним. Кроме того, аммиак относится к пожаро-взрывоопасным веществам.

Как показали исследования, для переработки сульфокатионита перспективна десорбция концентрированными водными растворами хлорида или нитрата натрия [20]. Оказалось, что растворы хлорида и нитрата натрия десорбируют катионы щелочноземельных и редкоземельных металлов, алюминия, железа более эффективно, чем раствор нитрата аммония. При десорбции получается сорбент в $\mathrm{Na}^{+}$-форме. Его можно регенерировать в $\mathrm{H}^{+}$-форму обработкой концентрированными кислотами, но при этом требуется утилизировать раствор, содержащий избыточную кислоту и соответствующую соль натрия.

Расчет коэффициентов распределения $K_{d}$ с использованием данных [18] и уравнения

$$
K_{d}=\frac{C_{\kappa} \cdot V_{p}}{\left(100-C_{\kappa}\right) \cdot V_{c}},
$$

где $C_{\kappa}$ - сорбция компонента, $V_{p}$ и $V_{c}$ - соответственно, объемы раствора и сорбента, показал, что при сорбции из фосфорнокислых растворов $K_{d}$ натрия и калия значительно меньше, чем щелочноземельных и редкоземельных элементов (РЗЭ). Следовательно, основные катионы апатитового концентрата образуют значительно более прочные связи с функциональной группой $-\mathrm{SO}_{3}$ сорбента, чем катионы натрия или калия и, хотя катионы натрия или калия будут затруднять их поглощение сорбентом, сорбция может проходить в приемлемой степени.

Целью работы являлось исследование возможности использования для переработки апатитового концентрата сульфокатионита в $\mathrm{Na}^{+}$- или
$\mathrm{K}^{+}$-форме с получением очищенной ортофосфорной кислоты.

\section{МЕТОДИКА ЭКСПЕРИМЕНТА}

В работе использовали апатитовый концентрат производства ОАО «Апатит-Фосагро» (ГОСТ 22275-90). Состав концентрата (мас.\%): $0,93 \mathrm{Na}_{2} \mathrm{O}$, $0,26 \mathrm{~K}_{2} \mathrm{O}, 50,0 \mathrm{CaO}, 3,11 \mathrm{SrO}, 0,62 \mathrm{Al}_{2} \mathrm{O}_{3}, 1,04$ $\sum \mathrm{Tr}_{2} \mathrm{O}_{3}, 0,31 \mathrm{TiO}_{2}, 0,71 \mathrm{Fe}_{2} \mathrm{O}_{3}, 0,003 \mathrm{ThO}_{2}, 0,00045$ $\mathrm{UO}_{2}, 39,06 \mathrm{P}_{2} \mathrm{O}_{5}$ и $3,03 \mathrm{~F}$.

Сульфокатиониты в $\mathrm{Na}^{+}$- или $\mathrm{K}^{+}$-формах готовили обработкой сорбента КУ-2-8чС (ГОСТ 20298-74) в $\mathrm{H}^{+}$-форме раствором фосфорнокислого натрия или калия. Полноту замещения протона на катионы $\mathrm{Na}^{+}$или $\mathrm{K}^{+}$, достигавшую $100 \%$, оценивали по изменению количества этих катионов в растворе после завершения обработки.

Навеску апатитового концентрата и заданное количество сорбента помещали в раствор $\mathrm{H}_{3} \mathrm{PO}_{4}$ (марка «Х.ч.», ГОСТ 6552-80) концентрацией $C_{H_{3}} \mathrm{PO}_{4}=32$ мас.\%. Пульпу перемешивали 4 ч при заданной температуре. Расход сорбента $\alpha$ оценивали в процентах от теоретически необходимого для сорбции катионов концентрата, рассчитанного в предположении, что они сорбируются в виде $\mathrm{Me}^{\mathrm{nt}}$.

После взаимодействия сорбент отделяли на сетчатом фильтре, из маточной пульпы отфильтровывали и промывали водой твердый остаток. Содержание катионов в маточном растворе и твердом остатке определяли аттестованным масс-спектрометрическим методом с индуктивно связанной плазмой (масс-спектрометр «ELAN 9000 DRC-е» (Perkin Elmer, США). Концентрацию фосфора в продуктах анализировали спектрофотометрическим, фтора - потенциометрическим методом. Количество поглощённых сорбентом компонентов рассчитывали по разности их количества в исходном концентрате и суммы количеств в фосфорнокислом растворе и твердом остатке. Степень разложения концентрата оценивали по суммарному извлечению кальция в сорбент и раствор. При промывке осадков водой содержащие фтор соединения частично растворялись, поэтому содержание фтора в осадках не определяли.

\section{РЕЗУЛЬТАТЫ И ИХ ОБСУЖДЕНИЕ}

Условия и результаты опытов по сорбционной конверсии хибинского апатитового концентрата приведены в табл. 1-4.

Как видно из данных табл. 1-4, при использовании сорбентов в $\mathrm{Na}^{+}$- и $\mathrm{K}^{+}$-форме может достигаться высокая степень разложения апатитового 
концентрата. При $20{ }^{\circ} \mathrm{C}$ увеличение расхода сорбента в $\mathrm{Na}^{+}$- или $\mathrm{K}^{+}$-форме в 1,5 раза снижало концентрацию кальция в полученном фосфорнокислом растворе и увеличивало количество поглощенного сорбентом кальция - основного катионного компонента апатитового концентрата (см. опыты 1 и 2,5 и 6). При сопоставимых условиях сорбент в $\mathrm{K}^{+}$-форме более эффективно поглощал кальций и Р3Э (см. опыты 2 и 6).

Полученные фосфорнокислые растворы содержали значительные концентрации натрия или калия, что приводило к осаждению значительной части содержащегося в апатитовом концентрате

Таблица 1

Зависимость степени разложения апатитового концентрата $\beta$ от условий проведения процесса (Ж объем фосфорнокислого раствора, Т - масса апатитового концентрата)

Table 1. The degree of apatite concentrate decomposition $\beta$ as a function of process conditions ( $Ж$ - volume of phosphoric acid solution, $\mathbf{T}$ - mass of apatite concentrate))

\begin{tabular}{|c|c|c|c|c|c|}
\hline Опыт & Ж:Т & $\alpha, \%$ & Форма & $\mathrm{t},{ }^{\circ} \mathrm{C}$ & $\beta$, отн.\% \\
\hline 1 & 12 & 115 & $\mathrm{Na}^{+}$ & 20 & 89,1 \\
\hline 2 & 12 & 170 & $\mathrm{Na}^{+}$ & 20 & 89,7 \\
\hline 3 & 12 & 115 & $\mathrm{Na}^{+}$ & 50 & 98,3 \\
\hline 4 & 17 & 115 & $\mathrm{Na}^{+}$ & 50 & 99,5 \\
\hline 5 & 12 & 115 & $\mathrm{~K}^{+}$ & 20 & 80,8 \\
\hline 6 & 12 & 165 & $\mathrm{~K}^{+}$ & 20 & 95,8 \\
\hline
\end{tabular}

Извлечение $\varepsilon$ основных металлов в сорбент Table 2. The isolation $\varepsilon$ of base metals into the sorbent

\begin{tabular}{|c|c|c|c|c|c|}
\hline \multirow{2}{*}{ Опыт } & \multicolumn{5}{|c|}{$\varepsilon$, отн. $\%$} \\
\cline { 2 - 6 } & $\mathrm{Na}$ & $\mathrm{K}$ & $\mathrm{Ca}$ & $\mathrm{Sr}$ & $\mathrm{Al}$ \\
\hline 1 & - & 74,2 & 73,3 & 82,9 & 35,5 \\
\hline 2 & - & 70,0 & 83,1 & 79,6 & 31,6 \\
\hline 3 & - & 23,6 & 78,3 & 83,9 & 9,12 \\
\hline 4 & - & 59,7 & 90,2 & 83,7 & 7,50 \\
\hline 5 & 12,6 & - & 72,8 & 72,9 & 26,2 \\
\hline 6 & 77,7 & - & 90,2 & 93,4 & 42,7 \\
\hline & $\mathrm{Ti}$ & $\mathrm{Fe}$ & $\mathrm{Th}$ & $\mathrm{U}$ & $\sum \mathrm{Tr}$ \\
\hline 1 & 74,0 & 56,9 & 0,66 & 11,1 & 64,8 \\
\hline 2 & 63,8 & 54,8 & 6,63 & 24,7 & 70,1 \\
\hline 3 & 69,2 & 57,8 & 22,1 & 24,8 & 52,0 \\
\hline 4 & 66,9 & 59,4 & 16,3 & 23,1 & 55,3 \\
\hline 5 & 67,4 & 57,4 & 22,8 & 29,4 & 59,6 \\
\hline 6 & 77,4 & 67,1 & 32,1 & 27,1 & 84,4 \\
\hline & $\mathrm{Y}$ & $\mathrm{La}$ & $\mathrm{Ce}$ & $\mathrm{Eu}$ & $\mathrm{Yb}$ \\
\hline 1 & 43,0 & 76,2 & 65,3 & 40,7 & 30,7 \\
\hline 2 & 58,9 & 75,2 & 69,8 & 58,8 & 49,5 \\
\hline 3 & 25,7 & 64,9 & 49,2 & 35,9 & 6,59 \\
\hline 4 & 33,4 & 68,4 & 51,4 & 39,7 & 22,8 \\
\hline 5 & 43,7 & 69,0 & 57,3 & 46,0 & 29,0 \\
\hline 6 & 71,8 & 89,0 & 85,3 & 71,4 & 58,6 \\
\hline
\end{tabular}

Таблица 3

Содержание катионных примесей в фосфорнокислых растворах

Table 3. The concent of main cation impurities in the phosphoric acid solutions

\begin{tabular}{|c|c|c|c|c|c|}
\hline \multirow{2}{*}{ Опыт } & \multicolumn{5}{|c|}{ Концентрация, мг ${ }^{-1}$} \\
\cline { 2 - 6 } & $\mathrm{Na}_{2} \mathrm{O}$ & $\mathrm{K}_{2} \mathrm{O}$ & $\mathrm{CaO}$ & $\mathrm{SrO}$ & $\mathrm{Al}_{2} \mathrm{O}_{3}$ \\
\hline 1 & 19260 & 42 & 6560 & 168 & 286 \\
\hline 2 & 20310 & 21 & 2760 & 80 & 267 \\
\hline 3 & 28272 & 162 & 8330 & 376 & 466 \\
\hline 4 & 20426 & 58 & 5684 & 291 & 333 \\
\hline 5 & 609 & 32626 & 3310 & 207 & 353 \\
\hline 6 & 122 & 30550 & 2340 & 77 & 230 \\
\hline & $\mathrm{TiO}_{2}$ & $\mathrm{Fe}_{2} \mathrm{O}_{3}$ & $\mathrm{ThO}_{2}$ & $\mathrm{UO}_{2}$ & $\mathrm{Tr}_{2} \mathrm{O}_{3}$ \\
\hline 1 & 31,0 & 197 & 2,11 & 0,28 & 217 \\
\hline 2 & 20,9 & 138 & 1,60 & 0,20 & 105 \\
\hline 3 & 70,5 & 231 & 1,90 & 0,28 & 403 \\
\hline 4 & 50,5 & 151 & 1,41 & 0,20 & 265 \\
\hline 5 & 21,0 & 138 & 1,39 & 0,20 & 212 \\
\hline 6 & 17,7 & 121 & 1,50 & 0,20 & 106 \\
\hline
\end{tabular}

Таблица 4

Концентрация основных компонентов в осадках*

Table 4. The concentration of base components in the deposits*

\begin{tabular}{|c|c|c|c|c|c|}
\hline \multirow{2}{*}{ Опыт } & \multicolumn{5}{|c|}{ Содержание, мас.\% } \\
\cline { 2 - 6 } & $\mathrm{Na}_{2} \mathrm{O}$ & $\mathrm{K}_{2} \mathrm{O}$ & $\mathrm{CaO}$ & $\mathrm{SrO}$ & $\mathrm{Al}_{2} \mathrm{O}_{3}$ \\
\hline 1 & 0,53 & 0,08 & 51,1 & 3,08 & 0,06 \\
\hline 2 & 0,28 & 0,03 & 39,5 & 3,34 & 0,04 \\
\hline 3 & 1,52 & 0,15 & 42,2 & 2,55 & 0,19 \\
\hline 4 & 3,67 & 0,52 & 21,6 & 1,32 & 0,72 \\
\hline 5 & 0,44 & 1,72 & 49,5 & 3,06 & 0,18 \\
\hline 6 & 0,30 & 7,22 & 36,9 & 2,09 & 0,35 \\
\hline & $\mathrm{TiO}_{2}$ & $\mathrm{Fe}_{2} \mathrm{O}_{3}$ & $\mathrm{ThO}_{2}$ & $\mathrm{Tr}_{2} \mathrm{O}_{3}$ & $\mathrm{P}_{2} \mathrm{O}_{5}$ \\
\hline 1 & 0,41 & 0,56 & 0,0025 & 0,95 & 43,5 \\
\hline 2 & 0,16 & 0,36 & 0,0035 & 1,13 & 55,7 \\
\hline 3 & 0,55 & 1,17 & 0,0031 & 0,82 & 35,6 \\
\hline 4 & 1,68 & 3,33 & 0,012 & 1,43 & 19,3 \\
\hline 5 & 0,39 & 0,71 & 0,0034 & 0,86 & 41,0 \\
\hline 6 & 0,82 & 1,31 & 0,0023 & 0,69 & 23,9 \\
\hline
\end{tabular}

Примечание: *- Содержание $\mathrm{UO}_{2}$ обычно 0,0004 мас.\%

Note: * - The concentration of $\mathrm{UO}_{2}$ is usually $0.0004 \mathrm{wt} \%$

фтора в виде фторсиликатов натрия или калия. Известно, что в растворах многих минеральных кислот растворимость фторсиликата калия заметно меньше, чем фторсиликата натрия [21]. В фосфорнокислых растворах эта закономерность сохранилась: фактическая концентрация фтора при использовании сульфокатионита в $\mathrm{Na}^{+}$-форме оставила $\left(\right.$ мг $\left.{ }^{-1}{ }^{-1}\right) 425$ при $20^{\circ} \mathrm{C}$ и 520 при $50^{\circ} \mathrm{C}$, сульфокатионита в $\mathrm{K}^{+}$-форме 150-190. Это соответствовало степени осаждения фтора при использовании сульфокатионита в $\mathrm{Na}^{+}$-форме не менее $80 \%$, при использовании сульфокатионита в $\mathrm{K}^{+}$-форме не менее $92 \%$.

Изв. вузов. Химия и хим. технология. 2020 Т. 63. Вып. 1 
При использовании сорбента в $\mathrm{Na}^{+}$-форме растворы в пересчете на 100 мас. $\% \mathrm{H}_{3} \mathrm{PO}_{4}$ содержат не более 0,11 мас.\%, а при использовании сорбента в $\mathrm{K}^{+}$-форме 0,05 мас.\% фтора. Таким образом, для большинства технических применений, например, производства кормового фосфата кальция по ГОСТ 23999-80, отпадает необходимость проведения дополнительной очистки получающейся фосфорной кислоты от примеси фтора.

В осадках опытов с величиной $\beta<90 \%$ отношение содержаний фосфора и кальция больше, чем в исходном апатитовом концентрате. Отсюда следует, что эти осадки кроме неразложившегося апатита и фторсиликата щелочного металла содержат образующийся в процессе фосфат кальция, вероятно, $\mathrm{Ca}\left(\mathrm{H}_{2} \mathrm{PO}_{4}\right)_{2} \cdot \mathrm{H}_{2} \mathrm{O}$. Повышенное содержание в осадках примесей $\mathrm{Mg}$, $\mathrm{Ti}, \mathrm{Fe}$ указывает на то, что в них концентрировались трудно разлагающиеся в процессе акцессорные минералы (эгирин, полевые шпаты, сфен и др.).

Увеличение температуры процесса до $50^{\circ} \mathrm{C}$ улучшало растворение апатита, но ухудшало эффективность конверсии вследствие возраставшего затруднения сорбции, вероятно, из-за более сильного упрочнения связей функциональных групп сорбента с катионом натрия по сравнению со связями с поливалентными катионами. Это проявлялось в снижении $K_{d}$ большинства металлов: для К в $4,5, \mathrm{Ca}$ в $1,2, \mathrm{Sr}$ в $2,2, \mathrm{Al}$ в $6, \sum \mathrm{Tr}$ и $\mathrm{Ti}$ в 2,4 раза. Исключением являлись железо(III), торий и уран, $K_{d}$ которых мало менялись или возрастали. Возрастание при повышении температуры величин $K_{d}$ тория и урана связано с распадом их анионных фосфатных комплексов или нейтральных молекул, приводящим к увеличению в растворе долей этих элементов в виде катионных комплексов. При использовании сорбента в $\mathrm{Na}^{+}$-форме (опыты 3 и 4) увеличение величины Ж:Т в 1,4 раза несколько снижало концентрации катионных примесей в растворе, но они оставались достаточно высокими.

В изученных условиях РЗЭ, особенно, иттрий и лантаноиды средней и иттриевой групп, сорбировались хуже щелочноземельных металлов. Эффективность сорбции РЗЭ увеличивалась с возрастанием их основности. При равных условиях их поглощение сорбентом в $\mathrm{K}^{+}$-форме было значительно больше, чем сорбентом в $\mathrm{Na}^{+}$-форме, но меньше, чем сорбентом в $\mathrm{H}^{+}$-форме [18].

Поглощение сорбентом тория, являющегося основным источником радиоактивности хибинского апатитового концентрата, при пониженном расходе сорбента уменьшается. За счет этого увеличивается эффективность отделения тория от других металлов. Хотя основная часть тория остается в фосфорнокислом растворе, удельная эффективная радиоактивность раствора очень мала.

При использовании сорбента в $\mathrm{Na}^{+}$-форме величины $K_{d}$ для большинства катионов меньше, чем полученные при использовании сорбента в $\mathrm{K}^{+}$форме. Это указывает на большую прочность связи катиона натрия с сульфогруппой сорбента по сравнению с катионом калия, ионный радиус которого на $\approx 36 \%$ больше, чем натрия. Исключением являлся торий, сорбция которого, напротив, возрастала, а содержание в маточных растворах немного снижалось.

Полученные при использовании сорбентов в $\mathrm{Na}^{+}$- или $\mathrm{K}^{+}$-форме фосфорнокислые растворы содержат высокие концентрации щелочных элементов, что не позволяет их использовать в обороте для разложения апатитового концентрата.

Исследовали отделение щелочных металлов методом электродиализа. В опытах по электродиализной очистке фосфатных растворов использовали двухкамерный электролизер фильтр-прессного типа с катионообменной мембраной МА-40 (функциональная группа - $\mathrm{SO}_{3} \mathrm{H}$ ), платиновым анодом и титановым катодом. Исходный раствор подавали в анодную камеру.

Предварительные опыты показали, что при проведении электродиализа на катиообменной мембране образуется осадок, который по данным рентгенофазового анализа состоял из гидроксилапатита $\mathrm{Ca}_{5}\left(\mathrm{PO}_{4}\right)_{3} \mathrm{OH}$. Для предотвращения образования этого осадка проводили предварительную сорбционную очистку фосфорнокислых растворов. При этом использовали сорбенты в той же форме, которая использовалась при сорбционной конверсии апатитового концентрата.

Сорбционную доочистку при $20{ }^{\circ} \mathrm{C}$ обогащенного натрием фосфорнокислого раствора проводили в течение 2 ч и соотношении $V_{p}: V_{c}=1,1: 1$, и обогащенного калием фосфорнокислого раствора в течение 4 ч и соотношении $V_{p}: V_{c}=0,65: 1$.

В процессе доочистки содержание щелочных элементов в растворе увеличилось на $\approx 20 \%$, но снизилось содержание Са в 8,6 и $21,6, \mathrm{Sr}$ в 17,8 и 45,2 , Р3Э в 3,5 и 8 раз для сорбентов в $\mathrm{Na}^{+}-$и $\mathrm{K}^{+}-$ формах, соответственно. Очистка от примесей $\mathrm{Al}$, $\mathrm{Ti}, \mathrm{Fe}$, Th и U при использовании сорбента в $\mathrm{Na}^{+}-$ форме не проходила, а при использовании сорбента в $\mathrm{K}^{+}$- форме была заметна лишь для $\mathrm{Al}(1,8$ раза), $\mathrm{Ti}$ и $\mathrm{Fe}(1,2$ раза). Низкая эффективность очистки от $\mathrm{Al}$, $\mathrm{Ti}, \mathrm{Fe}, \mathrm{Th}$ и U объясняется тем, что в исследовавшихся фосфорнокислых растворах основная часть 
алюминия, титан, железо, торий и уран входят в состав анионных комплексов или недиссоциированных молекул, в условиях эксперимента медленно переходящих в катионные комплексы.

Тем не менее, содержание катионных примесей в получаемой фосфорной кислоте даже без доочистки значительно меньше, чем в фосфорной кислоте, получаемой при сернокислотной переработке апатитового концентрата, которая по данным [4] содержит $\left(\Gamma \cdot \pi^{-1}\right): \mathrm{CaO} 3,7-10,0, \mathrm{Fe}_{2} \mathrm{O}_{3}$ 2,5-5,0, $\mathrm{Al}_{2} \mathrm{O}_{3}$ 1,2-6,2, $\Sigma \mathrm{Tr}_{2} \mathrm{O}_{3}$ 1,2-1,5. Полученные фосфорнокислые растворы не содержали сульфат-ион, а содержание фтора, как сообщалось выше, было достаточно низким.

Исследовали выделение $\mathrm{Na}$ и К методом электродиализа из предварительно дополнительно очищенных сорбцией фосфорнокислых растворов. Условия электродиализа: плотность тока 5-15 А·дм-2, отношение объемов анодной и катодной камер $1:(0,3-0,5)$. В зависимости от условий проведения электродиализа концентрация $\mathrm{NaOH}$ в католите составляла 68-105, КОН 87-97 $Г \cdot \pi^{-1}$ при выходах по току 20-31\% и извлечении натрия и калия 94,9$95,7 \%$.

В щелочные растворы попадает от 20 до $60 \%$ содержащихся в фосфорнокислых растворах щелочноземельных и редкоземельных элементов, алюминия. Минимальной миграцией в католит характеризуются уран $(2,9 \%)$, торий $(3,9 \%)$, титан (5 \%) и железо $(4,4 \%)$, что подтверждает их преимущественное существование в этих растворах в виде анионных фосфатных комплексов или нейтральных молекул.

\section{ЛИТЕР А Т У Р А}

1. Кудрин В.С., Чистов Л.Б. Состояние минерально-сырьевой базы редкоземельных металлов, перспективы ее развития и освоения. Минерал. ресурсы России. 1996. № 5. С. 6-12.

2. Soltani F., Abdollahy M., Petersen J., Ram R., Moradkhani D. Leaching and recovery of phosphate and rare earth elements from an iron-rich fluorapatite concentrate: Part II: Selective leaching of calcium and phosphate and acid baking of the residue. Hydrometallurgy. 2019. V. 184. N 1. P. 29-38.

3. Гольдинов А.Л., Копылев Б.А. Комплексная азотнокислотная переработка фосфатного сырья. Л.: Химия. 1982. 208 с.

4. Jorjani E., Bagherieh A.H., Chelgani S.C. Rare earth elements leaching from Chadormalu apatite concentrate: Laboratory studies and regression predictions. Korean J. Chem. Eng. 2011. V. 28. N 2. P. 557-562.

5. Wang Liangshi, Long Zhiqi, Huang Xiaowei, Yu Ying, Cui Dali, Zhang Guocheng. Recovery of rare earths from wet-process phosphoric acid. Hydrometallurgy. 2010. V. 101. N 1-2. P. 41-47.

6. Renteria-Villalobos M., Vioque I., Mantero J., Manjon G. Radiological, chemical and morphological characterizations of phosphate rock and phosphogypsum from phosphoric acid factories in SW Spain. J. Hazard. Mater. 2010. V. 181. N 1-3. P. 193-203.

7. Локшин Э.П., Тареева О.А. Выделение лантаноидов из экстракционной фосфорной кислоты дигидратного процесса. ЖПХ. 2010. Т. 83. № 6. С. 899-905.
Получающиеся растворы гидроксидов натрия или калия после карбонизации пригодны для ступенчатой нейтрализации элюатов, получающихся при десорбции из сульфокатионита катионов апатитового концентрата концентрированными растворами солей натрия, с последовательным осаждением редкоземельного концентрата, карбоната кальция и стронциевого концентрата и регенерацией используемого для десорбции раствора.

\section{ВЫВОДЫ}

В развитие метода [18], включающего обработку при комнатной температуре апатитового концентрата фосфорнокислым раствором в присутствии содержащего сульфоксидные функциональные группы сорбента, показана возможность получения товарной фосфорной кислоты повышенного качества с использованием сорбента в $\mathrm{Na}^{+}$- или $\mathrm{K}^{+}$- формах.

Исследовано влияние формы и расхода сорбента, температуры процесса на эффективность сорбционной конверсии апатитового концентрата.

Использование соульфокатионита в $\mathrm{Na}^{+}-$и $\mathrm{K}^{+}$- формах позволяет упростить технологию за счет исключения операций регенерации сорбента в $\mathrm{H}^{+}$- форму и очистки получаемой фосфорной кислоты от примеси фтора, но приводит к снижению извлечения РЗЭ, особенно, РЗЭ средней и иттриевой групп по сравнению с достигаемой при использовании сорбента в $\mathrm{H}^{+}$- форме.

\section{REFERENCES}

1. Kudrin V.S., Chistov L.B. The state of the mineral resource base of rare-earth metals, the prospects for its development and mastering. Mineral. Resursy Rossii. 1996. N 5. P. 6-12 (in Russian).

2. Soltani F., Abdollahy M., Petersen J., Ram R., Moradkhani D. Leaching and recovery of phosphate and rare earth elements from an iron-rich fluorapatite concentrate: Part II: Selective leaching of calcium and phosphate and acid baking of the residue. Hydrometallurgy. 2019. V. 184. N 1. P. 29-38.

3. Goldinov A.L., Kopylev B.A. Complex nitric acid processing of phosphate raw materials. L.: Khimiya. 1982. 208 p. (in Russian).

4. Jorjani E., Bagherieh A.H., Chelgani S.C. Rare earth elements leaching from Chadormalu apatite concentrate: Laboratory studies and regression predictions. Korean J. Chem. Eng. 2011. V. 28. N 2. P. 557-562.

5. Wang Liangshi, Long Zhiqi, Huang Xiaowei, Yu Ying, Cui Dali, Zhang Guocheng. Recovery of rare earths from wet-process phosphoric acid. Hydrometallurgy. 2010. V. 101. N 1-2. P. 41-47.

6. Renteria-Villalobos M., Vioque I., Mantero J., Manjon G. Radiological, chemical and morphological characterizations of phosphate rock and phosphogypsum from phosphoric acid factories in SW Spain. J. Hazard. Mater. 2010. V. 181. N 1-3. P. 193-203.

7. Lokshin E.P., Tareeva O.A. Isolation of lanthanides from extraction phosphoric acid of dihydrate process. Zhurn. Prikl. Khim. 2010. V. 83. N 6. P. 899-905 (in Russian). 
8. Локшин Э.П., Тареева О.А., Елизарова И.Р., Калинников В.T. Извлечение редкоземельных элементов из экстракционной фосфорной кислоты. ЖПХ. 2015. Т. 88. № 1. С. 3-14. DOI 10.1134/S1070427215010012.

9. Singh M. Treating waste phosphogypsum for cement and plaster manufacture. Cement concr. res. 2003. V. 32. P. 1033-1038.

10. Potgieter J.H., Potgieter S.S., McCrindle R.I., Strydom C.A. An investigation into the effect of various chemical and physical treatments of a South African phosphogypsum to render it suitable as a set retarder for cement. Cement concr. res. 2003. V. 33. P. 1223-1227.

11. Колокольников В.А., Ковалев М.И. Технология переработки технического карбоната кальция, полученного из фосфогипса, на чистый углекислый кальций и концентрат редкоземельных элементов. Химия в интересах устойчив. развития. 2009. Т. 17. № 4. С. 393-399.

12. Сизяков В.М., Нутрихина С.В., Левин Б.В. Технология комплексной переработки фосфогипса конверсионным способом с получением сульфата аммония, фосфомела и новых продуктов. Зап. Горн. ин-та. 2012. Т. 197. С. 239-244.

13. Локшин Э.П., Тареева О.А. Получение из фосфогипса качественного гипсового сырья. ЖПХХ. 2015. Т. 88. № 4. С. 534-540. DOI: $10.1134 / \mathrm{S} 1070427215040023$.

14. Локшин Э.П., Тареева О.А., Елизарова И.Р. Агитационное выщелачивание РЗЭ из фосфогипса сернокислыми растворами низких концентраций. Хим. технология. 2015. № 8. C. 487-493. DOI 10.1134/S0040579516050134.

15. Кочетков С.П., Смирнов Н.Н., Ильин А.П. Концентрирование и очистка экстракционной фосфорной кислоты. Иваново: Иван. гос. хим.-технол. ун-т. 2007. 304 с.

16. Смирнова Д.Н., Смирнов Н.Н., Ильин А.П., Кочетков С.П. Проблемы и перспективы производства и квалифицирования фосфорной кислоты. Известия вузов. Химия и хим. технология. 2017. Т. 60. Вып. 7. С. 48-56.

17. Локшин Э.П., Тареева О.А., Елизарова И.Р. Новый подход к переработке апатитового концентрата. ЖПХ. 2016. Т. 89. № 7. С. 887-893. DOI: 10.1134/S1070427216070065.

18. Локшин Э.П., Тареева О.А., Елизарова И.Р. Выделение редкоземельных элементов из растворов аммонийных солей. Хим. технология. 2014. № 4. С. 222-226.

19. Локшин Э.П., Тареева О.А., Елизарова И.Р. Переработка сульфокатионита, насыщавшегося в процессе фосфорнокислотного разложения хибинского апатитового концентрата. Хим. технология. 2019. Т. 20. № 4. C.163-170. DOI: 10.31044/1684-5811-2019-20-4-163-170.

20. Frayret J., Castetbon A., Trouve G., Potin-Gautier M. Solubility of $\left(\mathrm{NH}_{4}\right)_{2} \mathrm{SiF}_{6}, \mathrm{~K}_{2} \mathrm{SiF}_{6}$ and $\mathrm{Na}_{2} \mathrm{SiF}_{6}$ in acidic solutions. Chem. Phys. Lett. 2006. V. 427. P. 356-364. DOI: 10.1016/j.cplett.2006.06.044.
8. Lokshin E.P., Tareeva O.A., Elizarova I.R., Kalinnikov V.T. Recovery of rare earth elements from the wet process phosphoric acid. Russ. J. Appl. Chem. 2015. V. 88. N 1. P. 1-12. DOI 10.1134/S1070427215010012.

9. Singh M. Treating waste phosphogypsum for cement and plaster manufacture. Cement concr. res. 2003. V. 32. P. 1033-1038.

10. Potgieter J.H., Potgieter S.S., McCrindle R.I., Strydom C.A. An investigation into the effect of various chemical and physical treatments of a South African phosphogypsum to render it suitable as a set retarder for cement. Cement concr. res. 2003. V. 33. P. 1223-1227.

11. Kolokolnikov V.A., Kovalyov M.I. The technology of processing technical calcium carbonate obtained from phosphogypsum into pure calcium carbonate and rare earth concentrate. Khim. Interesakh Ustoych. Razvit. 2009. V. 17. N 4. P. 393-399 (in Russian).

12. Sizaikov V.M., Nutrikhina S.V., Levin B.V. The technology of complex processing of phosphogypsum by the conversion method to produce ammonium sulfate, phosphomel and new products. Zap. Gorn. In-ta. 2012. V. 197. P. 239-244 (in Russian).

13. Lokshin E.P., Tareeva O.A. Production of high-quality gypsum raw materials from phosphogypsum. Russ. J. Appl. Chem. 2015. V. 88. N 4. P. 567-573. DOI: $10.1134 / \mathrm{S} 1070427215040023$.

14. Lokshin E.P., Tareeva O.A., Elizarova I.R. Agitation laching of rare earth elements from phosphogypsum by weak sulfuric solutions. Theor. Found. Chem. Eng. 2016. V. 50. N 5. P. 857-862. DOI 10.1134/S0040579516050134.

15. Kochetkov S.P., Smirnov N.N., Ilyin A.P. Concentration and purification of extraction phosphoric acid. Ivanovo: ISUCT. 2007. $304 \mathrm{p}$ (in Russian).

16. Smirnova D.N., Smirnov N.N., Ilyin A.P., Kochetkov S.P. Problems and prospects of production and qualification of phosphoric acid. Izv. Vyssh. Uchebn. Zaved. Khim. Khim.Tekhnol. 2017. V. 60. N 7. P. $48-56$ (in Russian).

17. Lokshin E.P., Tareeva O.A., Elizarova I.R. New approach to processing of the apatite concentrate. Russ. J. Appl. Chem. 2016. V. 89. N 7. P. 1082-1088. DOI: $10.1134 /$ S1070427216070065.

18. Lokshin E.P., Tareeva O.A., Elizarova I.R. Isolation of rare earth elements from ammonium salts solutions. Theor. Found. Chem. Eng. 2015. V. 49. N 4. P. 555-559. DOI 10.1134/S0040559515040144.

19. Lokshin E.P., Tareeva O.A., Elizarova I.R. Processing sulfocationionite saturated during the phosphoric acid decomposition of the Khibiny apatite concentrate. Khim. Tekhnol. 2019. V. 20. N 4. P. 163-170 (in Russian). DOI: 10.31044/1684-5811-2019-20-4163-170.

20. Frayret J., Castetbon A., Trouve G., Potin-Gautier M. Solubility of $\left(\mathrm{NH}_{4}\right)_{2} \mathrm{SiF}_{6}, \mathrm{~K}_{2} \mathrm{SiF}_{6}$ and $\mathrm{Na}_{2} \mathrm{SiF}_{6}$ in acidic solutions. Chem. Phys. Lett. 2006. V. 427. P. 356-364. DOI: 10.1016/j.cplett.2006.06.044.

Поступила в редакцию (Received) 11.06.2018 Принята к опубликованию (Accepted) 15.11.2019 